\title{
Crystal Structure of Propyltriphenylphosphonium Dibromocuprate(I), $\left[\mathrm{P}\left(\mathrm{C}_{3} \mathrm{H}_{7}\right)\left(\mathrm{C}_{6} \mathrm{H}_{5}\right)_{3}\right]\left[\mathrm{CuBr}_{2}\right]$
}

\section{STAFFAN ANDERSSON and SUSAN JAGNER}

\author{
Department of Inorganic Chemistry, Chalmers University of Technology and University of \\ Göteborg, S-412 96 Göteborg, Sweden
}

Crystalline tetraphenylphosphonium and tetraalkylammonium bromocuprates(I) have been found to contain discrete anions, of various stoichiometries, in which copper(I) is two- or three-coordinated..$^{1-5}$ Calculation of the ligand concentrations in these and related compounds indicates that the configuration of the anion is determined by the degree of dilution imposed on the ligands by the cations. ${ }^{6}$ In order to examine the effect of the size of the cation further, as well as that of lack of symmetry with respect to exposure of the positive charge, attempts are being made to prepare crystalline bromocuprates(I) containing unsymmetrical tetraalkylammonium and related cations. $A$ discrete planar $\left[\mathrm{Cu}_{2} \mathrm{Br}_{4}\right]^{2-}$ dimer, similar to that in the tetraethylammonium compound, ${ }^{4}$ has been obtained with phenyltrimethylammonium as cation. ${ }^{7}$ Ethyltriphenylphosphonium dibromocuprate(I) has, however, been found to contain a nearly linear $\left[\mathrm{CuBr}_{2}\right]^{-}$monomer. ${ }^{8}$ Propyltriphenylphosphonium, which is slightly larger than ethyltriphenylphosphonium, would also be expected to crystallize with a monomeric dibromocuprate(I) ion. In order to confirm this hypothesis, crystals of ethyltriphenylphosphonium dibromocuprate(I) have been prepared and the structure of the compound determined from single-crystal X-ray diffractometer data.

Propyltriphenylphosphonium dibromocuprate(I) was prepared by dissolving propyltriphenylphosphonium bromide and copper(I) bromide (molar ratio 1:1) in ethanol. Colourless needles were deposited from the concentrated solution after a few days. Crystals of $\left[\mathrm{P}\left(\mathrm{C}_{3} \mathrm{H}_{7}\right)\left(\mathrm{C}_{6} \mathrm{H}_{5}\right)_{3}\right]\left[\mathrm{CuBr}_{2}\right], M_{r}=528.7$, are monoclinic, space group $P 2_{1} / n$ (No. 14, ${ }^{9 \mathrm{a}}$ non-standard setting), with $a=10.222(4), b=13.423(6), c=15.814(8) \AA, \beta=98.05(4)^{\circ}, Z=4$, $D_{c}=1.64 \mathrm{~g} \mathrm{~cm}^{-3}$ and $\mu(\mathrm{MoK} \alpha)=5.07 \mathrm{~mm}^{-1}$.

Diffracted intensities from a crystal, $0.53 \times 0.34 \times 0.27 \mathrm{~mm}$, were measured at approximately $290 \mathrm{~K}$ for $2 \theta \leq 50^{\circ}$ with a Syntex $P 2_{1}$ diffractometer, using graphite-monochromated MoKa radiation and the $\omega-2 \theta$ scan mode with a variable $2 \theta$ scan rate of $2.5-29.3^{\circ} \mathrm{min}^{-1}$. A 96-step profile was recorded for each reflection and the Lehmann and Larsen profileanalysis method ${ }^{10}$ was used to calculate the intensities. ${ }^{11}$ Of the 3804 independent reflections measured, excluding those systematically absent, 2219 had $I>3.0 \sigma(I)$ and were considered observed. Correction was made for Lorentz and polarisation effects; an empirical correction ${ }^{12}$ for the effects of absorption was made after solution of the structure. The unit-cell dimensions were determined from diffractometer setting angles for 15 reflections.

The atomic coordinates of the anion and subsequently those of the cation were determined by direct methods (MITHRIL; ${ }^{13}$ DIRDIF ${ }^{14}$ ). Full-matrix least-squares refinement $^{15}$ of positional and isotropic thermal parameters gave $R=0.097$; after an empirical correction $^{12}$ for the effects of absorption $R=0.075$. Inclusion of anisotropic thermal parameters and of positional parameters for the hydrogen atoms (located from a difference map ${ }^{15}$ ), the isotropic thermal parameters of the latter being set equal to the equivalent isotropic values of the carrying carbon atoms (see Table 1) gave a final $R$ of 0.037 (292 parameters; 2219 reflections). Atomic scattering factors were taken from the International Tables for $X$-Ray Crystallography ${ }^{9 \mathrm{~b}}$ and the $F_{o}$ values were weighted according to $w=\left[\sigma^{2}\left(F_{o}\right)+0.0006 F_{o}^{2}\right]^{-1}$. A final difference map showed a maximum electron density of 0.32 $\mathrm{e}^{-3}$. Atomic coordinates and equivalent isotropic thermal parameters for the nonhydrogen atoms are given in Table 1 . Structure factors, anisotropic thermal parameters, hydrogen-atom coordinates, carbon-hydrogen distances, and bond angles within the cation may be obtained from the authors.

Discussion. As expected, the anion in propyltriphenylphosphonium dibromocuprate(I) is monomeric (Fig. 1). The geometries of monomeric dibromocuprate(I) ions determined in 
Table 1. Fractional coordinates and equivalent isotropic thermal parameters $\left(\AA^{2}\right)$ for the non-hydrogen atoms in $\left[\mathrm{P}\left(\mathrm{C}_{3} \mathrm{H}_{7}\right)\left(\mathrm{C}_{6} \mathrm{H}_{5}\right)_{3}\right]\left[\mathrm{CuBr}_{2}\right]$. $B_{\mathrm{eq}}$ is defined as $8 \pi^{2} / 3 \sum_{i j} \sum_{j} U_{i j} a_{i}^{*} a_{j}^{*} a_{i} \cdot \mathbf{a}_{j}$.
Estimated standard deviations are given in parentheses.

\begin{tabular}{|c|c|c|c|c|}
\hline Atom & $x$ & $y$ & $z$ & $B_{\text {eq }}$ \\
\hline $\mathrm{Cu}$ & $0.72199(7)$ & $0.06569(5)$ & $0.29463(4)$ & $5.21(2)$ \\
\hline $\operatorname{Br}(1)$ & $0.69789(7)$ & $0.11688(5)$ & $0.42588(4)$ & $6.20(2)$ \\
\hline $\operatorname{Br}(2)$ & $0.73353(7)$ & $0.03119(5)$ & $0.15826(4)$ & $6.27(2)$ \\
\hline $\mathbf{P}$ & $0.21041(13)$ & $0.03753(9)$ & $0.30506(8)$ & $3.46(3)$ \\
\hline $\mathrm{C}(11)$ & $0.1734(5)$ & $0.1512(3)$ & $0.3575(3)$ & $4.0(1)^{\prime}$ \\
\hline $\mathrm{C}(12)$ & $0.0471(6)$ & $0.1908(4)$ & $0.3417(4)$ & $5.0(2)$ \\
\hline $\mathrm{C}(13)$ & $0.0179(7)$ & $0.2810(5)$ & $0.3792(5)$ & $6.1(2)$ \\
\hline$C(14)$ & $0.1157(9)$ & $0.3306(5)$ & $0.4312(4)$ & $6.2(2)$ \\
\hline$C(15)$ & $0.2390(9)$ & $0.2929(5)$ & $0.4462(4)$ & $6.8(3)$ \\
\hline C(16) & $0.2724(6)$ & $0.2023(4)$ & $0.4107(4)$ & $5.2(2)$ \\
\hline $\mathrm{C}(21)$ & $0.0792(5)$ & $-0.0502(3)$ & $0.3104(3)$ & $3.7(1)$ \\
\hline $\mathrm{C}(22)$ & $0.0472(6)$ & $-0.1208(4)$ & $0.2474(4)$ & $5.1(2)$ \\
\hline $\mathrm{C}(23)$ & $-0.0484(7)$ & $-0.1926(4)$ & $0.2559(5)$ & $6.0(2)$ \\
\hline $\mathrm{C}(24)$ & $-0.1106(6)$ & $-0.1935(5)$ & $0.3274(5)$ & $6.1(2)$ \\
\hline$C(25)$ & $-0.0794(7)$ & $-0.1235(5)$ & $0.3905(5)$ & $6.4(2)$ \\
\hline$C(26)$ & $0.0164(6)$ & $-0.0521(4)$ & $0.3826(4)$ & $5.1(2)$ \\
\hline$C(31)$ & $0.2255(5)$ & $0.0662(3)$ & $0.1958(3)$ & $3.6(1)$ \\
\hline$C(32)$ & $0.3472(6)$ & $0.0867(5)$ & $0.1724(4)$ & $5.4(2)$ \\
\hline C(33) & $0.3578(8)$ & $0.1178(5)$ & $0.0902(4)$ & $6.4(2)$ \\
\hline$C(34)$ & $0.2466(8)$ & $0.1262(4)$ & $0.0299(4)$ & $6.1(2)$ \\
\hline C(35) & $0.1256(8)$ & $0.1044(5)$ & $0.0533(4)$ & $6.6(2)$ \\
\hline$C(36)$ & $0.1127(7)$ & $0.0747(5)$ & $0.1351(4)$ & $5.3(2)$ \\
\hline C(41) & $0.3618(6)$ & $-0.0153(4)$ & $0.3577(3)$ & $4.3(2)$ \\
\hline$C(42)$ & $0.3946(7)$ & $-0.1177(5)$ & $0.3246(4)$ & $5.8(2)$ \\
\hline C(43) & $0.5223(8)$ & $-0.1596(6)$ & $0.3679(6)$ & $7.2(3)$ \\
\hline
\end{tabular}

compounds containing tetrabutylammonium, tetraphenylphosphonium and alkyltriphenylphosphonium cations are compared in Table 2 . There are small but statistically significant differences between $\mathrm{Cu}-\mathrm{Br}$ distances, both within individual anions and between anions in different compounds.

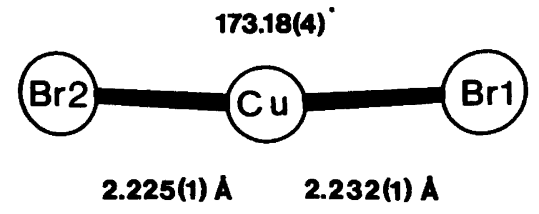

Fig. 1. The dibromocuprate(I) ion in $\left[\mathrm{P}\left(\mathrm{C}_{3} \mathrm{H}_{7}\right)\left(\mathrm{C}_{6} \mathrm{H}_{5}\right)_{3}\right]\left[\mathrm{CuBr}_{2}\right]$. Estimated standand deviations in the distances and angle are given in parentheses. The thermal ellipsoids enclose $50 \%$ probability. ${ }^{16}$

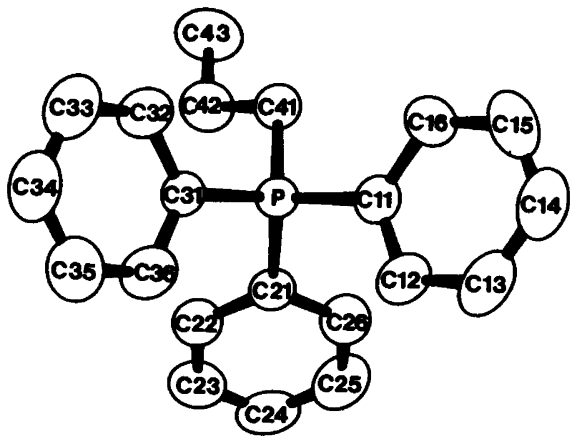

Fig. 2. The propyltriphenylphosphonium ion showing the atomic numbering. The thermal ellipsoids enclose $50 \%$ probability. ${ }^{16}$ Hydrogen atoms have been omitted.

Acta Chem. Scand. A 39 (1985) No. 8 
Table 2. Comparison of monomeric dibromocuprate(I) ions crystallizing with tetrabutylammonium, tetraphenylphosphonium and alkyltriphenylphosphonium cations. Distances are in $\AA$ and angles in ${ }^{\circ}$. The ligand concentration in the crystalline phase is given in mol dm ${ }^{-3}$.

\begin{tabular}{lcccc}
\hline Compound & $\mathrm{Cu}-\mathrm{Br}$ & $\mathrm{Br}-\mathrm{Cu}-\mathrm{Br}$ & {$[\mathrm{Br}]$} & Ref. \\
\hline$\left[\mathrm{N}\left(\mathrm{C}_{4} \mathrm{H}_{9}\right)_{4}\right]\left[\mathrm{CuBr}_{2}\right]$ & $2.226(1)$ & 180 & 6.36 & 2 \\
$\left.\mathrm{P}\left(\mathrm{C}_{6} \mathrm{H}_{5}\right)_{4}\right]\left[\mathrm{CuBr}_{2}\right]$ & $2.211(2)$ & $173.62(7)$ & 5.87 & 1 \\
{$\left[\mathrm{P}\left(\mathrm{C}_{3} \mathrm{H}_{7}\right)\left(\mathrm{C}_{6} \mathrm{H}_{5}\right)_{3}\right]\left[\mathrm{CuBr}_{2}\right]$} & $2.216(2)$ & & & \\
{$\left[\mathrm{P}\left(\mathrm{C}_{2} \mathrm{H}_{5}\right)\left(\mathrm{C}_{6} \mathrm{H}_{5}\right)_{3}\right]\left[\mathrm{CuBr}_{2}\right]$} & $2.225(1)$ & $173.18(4)$ & 6.18 & Present work \\
& $2.232(1)$ & & & 8 \\
\hline
\end{tabular}

Table 3. Interatomic distances $(\AA)$ within the propyltriphenylphosphonium cation. Estimated standard deviations are given in parentheses.

\begin{tabular}{llll}
\hline $\mathrm{P}-\mathrm{C}(11)$ & $1.803(5)$ & $\mathrm{C}(23)-\mathrm{C}(24)$ & $1.372(11)$ \\
$\mathrm{P}-\mathrm{C}(21)$ & $1.796(5)$ & $\mathrm{C}(24)-\mathrm{C}(25)$ & $1.376(10)$ \\
$\mathrm{P}-\mathrm{C}(31)$ & $1.798(5)$ & $\mathrm{C}(25)-\mathrm{C}(26)$ & $1.388(9)$ \\
$\mathrm{P}-\mathrm{C}(41)$ & $1.797(6)$ & $\mathrm{C}(26)-\mathrm{C}(21)$ & $1.385(8)$ \\
$\mathrm{C}(11)-\mathrm{C}(12)$ & $1.386(8)$ & $\mathrm{C}(31)-\mathrm{C}(32)$ & $1.375(8)$ \\
$\mathrm{C}(12)-\mathrm{C}(13)$ & $1.399(9)$ & $\mathrm{C}(32)-\mathrm{C}(33)$ & $1.383(9)$ \\
$\mathrm{C}(13)-\mathrm{C}(14)$ & $1.374(11)$ & $\mathrm{C}(33)-\mathrm{C}(34)$ & $1.383(11)$ \\
$\mathrm{C}(14)-\mathrm{C}(15)$ & $1.348(13)$ & $\mathrm{C}(34)-\mathrm{C}(35)$ & $1.371(11)$ \\
$\mathrm{C}(15)-\mathrm{C}(16)$ & $1.401(9)$ & $\mathrm{C}(35)-\mathrm{C}(36)$ & $1.378(9)$ \\
$\mathrm{C}(16)-\mathrm{C}(11)$ & $1.401(8)$ & $\mathrm{C}(36)-\mathrm{C}(31)$ & $1.397(8)$ \\
$\mathrm{C}(21)-\mathrm{C}(22)$ & $1.381(7)$ & $\mathrm{C}(41)-\mathrm{C}(42)$ & $1.525(8)$ \\
$\mathrm{C}(22)-\mathrm{C}(23)$ & $1.393(9)$ & $\mathrm{C}(42)-\mathrm{C}(43)$ & $1.497(11)$ \\
\hline
\end{tabular}
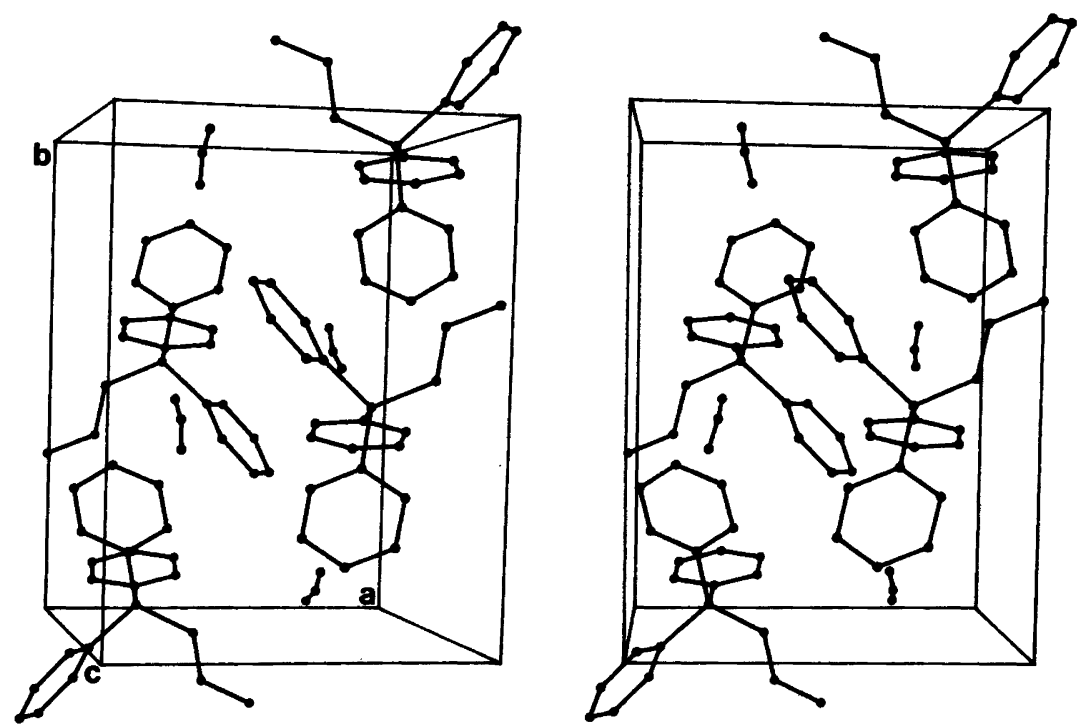

Fig. 3. Stereoscopic view ${ }^{16}$ of the unit cell. All atoms are represented as spheres of radius $0.05 \AA$. Hydrogen atoms have been omitted.

Acta Chem. Scand. A 39 (1985) No. 8 
The ligand concentration in the solid state (Table 2) is of the same order in all four compounds and is seen to decrease with decreasing size of the cation. That tetrabutylammonium, which is formally larger than the other cations, is associated with a higher ligand concentration than tetraphenylphosphonium and propyltriphenylphosphonium can undoubtedly be ascribed to the greater rigidity of the phenyl rings as compared with the butyl chains, leading to larger effective volumes for the two latter cations. A similar effect has been noted ${ }^{6}$ for tetrabutylammonium dichlorocuprate $(\mathrm{I})^{2}$ in comparison with the tetraphenylarsonium and tetraphenylphosphonium analogues ${ }^{1}$ and for bis(tetrabutylammonium) di- $\mu$-iodo-diiododicuprate(I) ${ }^{17}$ in comparison with the corresponding tetraphenylarsonium compound. ${ }^{18}$ The tetrabutylammonium cation would appear (Table 2 ) to have an effective volume intermediate between that of propyltriphenylphosphonium and that of ethyltriphenylphosphonium.

It would seem likely that the positive charges on all four cations cited in Table 2 are sufficiently well screened for the lack of symmetry with respect to charge exposure in the propyltriphenylphosphonium and ethyltriphenylphosphonium cations to be of less importance than the net size, for the determination of the anionic configuration. The ligand dilution in the solid state required for the attainment of discrete bromocuprate(I) species containing two-coordinated copper(I) would appear to lie between 6.50 and $10.3 \mathrm{~mol} \mathrm{dm}^{-3}$, which is the value obtained ${ }^{6}$ for $[\mathrm{Br}]$ in $\left[\mathrm{N}\left(\mathrm{C}_{3} \mathrm{H}_{7}\right)_{4}\right]_{2}\left[\mathrm{Cu}_{4} \mathrm{Br}_{6}\right]{ }^{3}$

The propyltriphenylphosphonium cation is depicted in Fig. 2 and distances within the cation are given in Table 3. There is less variation in the phosphorus-carbon distances in the present compound than in tetraphenylphosphonium dibromocuprate(I) and ethyltriphenylphosphonium dibromocuprate(I) where $\mathrm{P}-\mathrm{C}$ range from $1.768(7)-1.794(7) \AA,{ }^{1}$ and $1.756(10)-1.810(9) \AA,{ }^{8}$ respectively. As in ethyltriphenylphosphonium dibromocuprate(I), ${ }^{8}$ the shortest $\mathrm{Cu} \cdots \mathrm{C}$ contact is to a phenyl group, viz. $\mathrm{Cu} \cdots \mathrm{C}\left(25^{i}\right)=3.465(7) \AA$. This distance is intermediate between the shortest such distance in tetraphenylphosphonium dibromocuprate(I), 3.387(8) $\AA$, ${ }^{1}$ and that in ethyltriphenylphosphonium dibromocuprate(I), 3.56(1) $\AA^{8}{ }^{8}$ The shortest contact between bromide and carbon, $\operatorname{Br}(2) \cdots C\left(34^{i i}\right)=3.678(7) \AA$, is of the

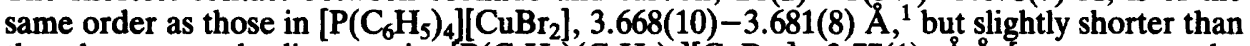
the shortest such distance in $\left[\mathrm{P}\left(\mathrm{C}_{2} \mathrm{H}_{5}\right)\left(\mathrm{C}_{6} \mathrm{H}_{5}\right)_{3}\right]\left[\mathrm{CuBr}_{2}\right], 3.77(1) \AA{ }^{8}$ [symmetry code: (i): $1+x, y, z$; (ii): $1-x, \bar{y}, \bar{z}]$.

Acknowledgement. Financial support from the Swedish Natural Science Research Council is gratefully acknowledged.

1. Andersson, S. and Jagner, S. Acta Chem. Scand. A 39 (1985) 297.

2. Asplund, M., Jagner, S. and Nilsson, M. Acta Chem. Scand. A 37 (1983) 57.

3. Asplund, M. and Jagner, S. Acta Chem. Scand. A 38 (1984) 725.

4. Asplund, M. and Jagner, S. Acta Chem. Scand. A 38 (1984) 135.

5. Asplund, M. and Jagner, S. Acta Chem. Scand. A 39 (1985) 47.

6. Andersson, S. and Jagner, S. Acta Chem. Scand. A 40 (1986). In press.

7. Andersson, S. and Jagner, S. Acta Chem. Scand. A 39 (1985) 423.

8. Andersson, S. and Jagner, S. Acta Chem. Scand. A 39 (1985) 515.

9. a. International Tables for X-Ray Crystallography, Kynoch Press, Birmingham 1952, Vol. I; b. Ibid. 1974, Vol. IV.

10. Lehmann, M.S. and Larsen, F.K. Acta Crystallogr. A 30 (1974) 580.

11. Lindqvist, O. and Ljungström, E. J. Appl. Crystallogr. 12 (1979) 134.

12. Walker, N. and Stuart, D. Acta Crystallogr. A 39 (1983) 158.

13. Gilmore, C.J. J. Appl. Crystallogr. 17 (1984) 42.

14. Beurskens, P.T., Bosman, W.P., Doesburg, H.M., Gould, R.O., van den Hark, T.E.M., Prick, P.A.J., Noordik, J.H., Beurskens, G. and Parthasarathi, V. DIRDIF: Direct Methods for Difference Structures, Technical Report 1981/2, Crystallography Laboratory, Toernooiveld, Nijmegen, Netherlands 1981. 
15. Lindgren, O. An Integrated Set of Crystallographic Programs. In On the Oxygen Coordination of Cerium in Some Sulfates and Chromates, Thesis, Department of Inorganic Chemistry, Chalmers University of Technology and University of Göteborg, Göteborg 1977.

16. Johnson, C.K. ORTEP: Report ORNL-3794, Oak Ridge National Laboratory, Oak Ridge 1965.

17. Asplund, M., Jagner, S. and Nilsson, M. Acta Chem. Scand. A 36 (1982) 751.

18. Asplund, M. and Jagner, S. Acta Chem. Scand. A 38 (1984) 297.

Received June 28, 1985. 